\title{
On the Foreign Exchange Risk Premium in Sticky-Price General Equilibrium Models
}

\author{
Charles Engel \\ University of Washington and NBER
}

First draft: December 18, 1998

This revision: March 29, 1999

This paper was prepared for the Festschrift for Robert Flood. I have borrowed heavily from joint work with Mick Devereux for this paper. I thank the discussants Jim Boughton and Dick Meese for helpful comments. Some of the work on this paper was done while I was a Visiting Scholar at the Federal Reserve Bank of San Francisco. The views expressed in this paper do not necessarily represent those of the FRB-SF or the Federal Reserve System. This research was supported in part by a National Science Foundation grant to the NBER. 
In general equilibrium models in which prices are perfectly flexible and output fluctuations occur solely because of supply shocks, the source of a foreign exchange risk premium is the correlation between supply shocks to output and shocks to the money supply (see Stulz (1984) and Engel (1992).) Monetary volatility or exchange rate volatility per se will not necessarily result in a risk premium. Monetary shocks that have no impact on consumption will not increase the riskiness of holding domestic or foreign nominal assets.

When nominal prices are sticky, however, monetary shocks will cause changes in output and consumption. While in sticky-price models the risk premium still arises from the covariance of exchange rates with consumption, it is inevitable that such a correlation will exist. A positive domestic monetary shock generally leads to a depreciation of the domestic currency and an increase in home consumption.

The first section of this paper briefly reviews the concept of the foreign exchange risk premium. There is a tradition in the literature of defining the risk premium as deviations from uncovered interest parity. Empirically, that is a useful approximation for a measure of the risk premium, but it can lead one astray in theoretical analyses of the determinants of the risk premium. Some of my previous papers (Engel $(1984,1992,1996))$ have discussed this issue extensively., so the discussion in section 1 will be short. Still, it is helpful to review this distinction because Obstfeld and Rogoff's (1998) analysis of the foreign exchange risk premium in their sticky-price general equilibrium model relies on the traditional (but somewhat misleading) definition of the risk premium.

Section 2 presents the sticky-price general equilibrium models. Again, this presentation is very abbreviated. That is because the models are drawn directly from Obstfeld and Rogoff (1998) and Devereux and Engel (1998). The distinction between these two models is that in the ObstfeldRogoff model, producers set prices in their own currency. The price paid by foreigners for home goods (and the price paid by domestic residents for foreign goods) varies instantaneously when the exchange rate changes. The law of one price holds. In the Devereux-Engel model, producers set a price in the home currency for domestic residents and in the foreign currency for foreign residents. When the exchange rate fluctuates, the law of one price does not hold. The type of price-setting behavior of producers matters for the size of the risk premium.

Another thing that matters for the size of the risk premium is the money demand function. For both models of price setting, the nature of the risk premium depends on whether money demand is derived from a real-balances-in-the-utility-function framework or a cash-in-advance framework.

Section 3 derives expressions for the foreign exchange risk premium in this matrix of models: prices set in producers' currencies versus consumers' currencies; and money demand derived from cash in advance versus real balances in the utility function.

Section 4 analyzes the findings. There are four main points:

1) While the existence of a risk premium in the flexible-price general equilibrium models depends on the correlation of exogenous monetary shocks and aggregate supply shocks, the risk premium arises endogenously in sticky-price models. Monetary variability induces correlation 
between consumption and exchange rates. This result is appealing in that the foreign exchange risk premium is directly related to the volatility of exchange rates, which is consistent with the finding of Flood and Rose (1996)

2) The distribution of aggregate supply shocks has no bearing on the foreign exchange risk premium in the sticky-price models we analyze.

3) Engel $(1984,1992,1996)$ shows the risk premium depends on the prices faced by consumers. When the law of one price does not hold, as in the model in which producers set prices in consumers' currencies, there is no unique foreign exchange risk premium. The risk premium for home investors is different from the risk premium for foreign investors.

4) Standard general equilibrium models are incapable of producing risk premiums that are very large. One sticky-price model we examine (prices set in consumers' currencies with a cash-inadvance constraint) can generate much larger risk premiums.

\section{The Foreign Exchange Rate Risk Premium}

A useful way analyze the risk premium implicit in the forward exchange rate (defined here as the home currency cost of buying a unit of foreign exchange one period forward) is to compare the forward rate to what it would be if investors were risk neutral. Let $F_{t}$ be the forward rate and $F_{t}^{R N}$ the risk-neutral forward rate.

If there were only a single consumption good, risk-neutrality implies that utility is linear in consumption. Engel (1984) argues that the risk-neutral investor would arbitrage the market until the condition:

$$
E_{t}\left(\frac{F_{t}^{R N}-S_{t+1}}{P_{t+1}}\right)=0
$$

holds, where $E_{t}$ refers to expectations conditional on time $t$ information; $S_{t}$ is the spot exchange rate (domestic price of foreign currency); and $P_{t}$ is the nominal domestic-currency price of the consumption good. In words, expression (1) means that under risk neutrality there are no expected real profits from forward market speculation.

Engel (1992) demonstrates that when utility is time separable, and felicity (period by period utility) is a function of more than one good, equation (1) still defines the risk-neutral forward rate. It is possible to write an expression such as (1) when felicity is homothetic. In this case, $P_{t}$ is the exact price index associated with the felicity function. Risk-neutrality means that felicity is linear in the consumption index, where the consumption index is defined as total nominal consumption expenditure in the period divided by the price index.

Equation (1) gives an expression for the risk-neutral forward rate: 


$$
F_{t}^{R N}=E_{t}\left(\frac{S_{t+1}}{P_{t+1}}\right) / E_{t}\left(\frac{1}{P_{t+1}}\right) .
$$

The risk premium is the defined by comparing $F_{t}$ to $F_{t}^{R N}$.

Hodrick (1987) and Engel (1996) show that in models where utility is time-separable with a constant rate of time preference that the actual forward rate is derived from the expression:

$$
E_{t}\left(\frac{F_{t}-S_{t+1}}{P_{t}} \cdot \frac{\beta u^{\prime}\left(C_{t+1}\right)}{u^{\prime}\left(C_{t}\right)}\right)=0,
$$

where $\beta$ is the discount factor in utility; $u(\cdot)$ is the felicity function; the prime (') indicates the first derivative; so

$$
A_{t+1} \equiv \frac{\beta u^{\prime}\left(C_{t+1}\right)}{u^{\prime}\left(C_{t}\right)}
$$

is the intertemporal marginal rate of substitution. $C_{t}$ is a real consumption index in the many-goods case.

If all variables are distributed log-normally, we can write equation (3) as

$$
f_{t}=E_{t}\left(s_{t+1}\right)+1 / 2 \operatorname{Var}_{t}\left(s_{t+1}\right)-\operatorname{Cov}_{t}\left(s_{t+1}, p_{t+1}\right)+\operatorname{Cov}_{t}\left(s_{t+1}, a_{t+1}\right),
$$

where lower-case letters are the natural logs of the corresponding variables in upper cases; and, Var $_{t}$ and $\mathrm{Cov}_{t}$ refer to the variance and covariance, respectively, conditional on time $t$ information.

When felicity can be written in the constant-relative-risk-aversion form, so:

$$
u\left(C_{t}\right)=\frac{1}{1-\rho} C_{t}^{1-\rho},
$$

equation (4) can be further specialized to:

$$
f_{t}=E_{t}\left(s_{t+1}\right)+1 / 2 \operatorname{Var}_{t}\left(s_{t+1}\right)-\operatorname{Cov}_{t}\left(s_{t+1}, p_{t+1}\right)-\rho \operatorname{Cov}_{t}\left(s_{t+1}, c_{t+1}\right) .
$$

Then, using equation (2), we can derive the expression for the risk premium as:

$$
r p_{t} \equiv f_{t}-f_{t}^{R N}=-\rho \operatorname{Cov}_{t}\left(s_{t+1}, c_{t+1}\right) .
$$


We can contrast this expression for the risk premium with the usual one in the literature (see most recently, Obstfeld and Rogoff (1998)), $f_{t}-E_{t}\left(s_{t+1}\right)$. From equation (5), we have immediately that

$$
f_{t}-E_{t}\left(s_{t+1}\right)=1 / 2 \operatorname{Var}_{t}\left(s_{t+1}\right)-\operatorname{Cov}_{t}\left(s_{t+1}, p_{t+1}\right)-\rho \operatorname{Cov}_{t}\left(s_{t+1}, c_{t+1}\right)
$$

The difference between this expression and the one given in equation (6) is the term $1 / 2 \operatorname{Var}_{t}\left(s_{t+1}\right)-\operatorname{Cov}_{t}\left(s_{t+1}, p_{t+1}\right)$, which is usually called the "Jensen's inequality" term. It is typically argued that the Jensen's inequality term is small empirically, and so it does not matter whether it is included as part of the definition of the risk premium.

But Engel (1996) shows that in standard general equilibrium models, the Jensen's inequality term generated from the model is just about the same size as the risk premium. While it is true that the Jensen's inequality terms is not large empirically, neither is the risk premium generated from standard models. One way of stating how poorly these models do in producing large risk premiums is that the risk premium the model generates is approximately the same size as the Jensen's inequality term, the latter of which is nearly universally recognized to be small.

Moreover, from the standpoint of economic intuition, the risk premium defined in equation (6) is much more useful than the standard measure. For example, holding the covariance constant in equation (6), the risk premium goes to zero as risk aversion disappears ( $\rho$ goes to zero). But, in the usual definition, there is a risk premium even when there is no risk aversion.

All of the models we will examine satisfy the conditions used in deriving expression (6): variables are distributed log-normally and utility is time-separable with constant time discounting and constant relative risk aversion.

\section{The Sticky-Price Models}

The models we consider are derived in detail in Devereux and Engel (1998). Here only the salient details of the model will be brought out.

We consider two sticky-price models:

PCP: In this model, there is producer-currency pricing. That is, producers set the price in their own currency. The price that foreigners pay for domestic goods and the price that home residents pay for foreign goods fluctuate when the exchange rate changes. This is the model examined by Obstfeld and Rogoff $(1995,1998)$.

PTM: In this model, there is pricing to market. That is, producers set the price in the consumers' currency. Prices consumers face do not respond at all to exchange rate changes.

The models are two-country models. In both models, the representative consumer in the home country is assumed to maximize 


$$
U_{t}=E_{t}\left(\sum_{s=t}^{\infty} \beta^{s-t} u_{s}\right), \quad 0<\beta<1
$$

where

$$
u_{s}=\frac{1}{1-\rho} C_{s}^{1-\rho}+\frac{\chi}{1-\varepsilon}\left(\frac{M_{s}}{P_{s}}\right)^{1-\varepsilon}-\eta V\left(L_{s}\right), \quad \rho>0, \varepsilon>0, V^{\prime}>0, V^{\prime \prime} \geq 0
$$

$C$ is a consumption index that is a geometric average of home and foreign consumption:

$$
C=\frac{C_{h}^{n} C_{f}^{1-n}}{n^{n}(1-n)^{1-n}}
$$

We assume that there are $n$ identical individuals in the home country, $0<n<1 . C_{h}$ and $C_{f}$ are Dixit-Stiglitz constant-elasticity-of -substitution indexes over consumption of goods produced at home and in the foreign country, respectively. (See Devereux and Engel (1998) for their exact form.) $M / P$ are domestic real balances, and $L$ is the labor supply of the representative home agent.

The price index, $P$, is defined by

$$
P=P_{h}^{n} P_{f}^{1-n}
$$

where $P_{h}$ is a price index over prices of home goods, and $P_{f}$ is a price index over prices of goods produced in the foreign country.

There are $1-n$ identical individuals in the foreign country. Their preferences are similar to home country residents' preferences. The terms in the utility function involving consumption are identical in the home and foreign countries. The functional form for real balances and labor are the same as for the home country residents, but, for foreign residents, they are functions of foreign real balances and foreign labor supply.

We assume that there are complete asset markets. Specifically, we assume that residents of each country can purchase state-contingent nominal bonds. We can write the budget constraint of the representative home agent as:

$$
P_{t} C_{t}+M_{t}+\sum_{z^{t+1}} q\left(z^{t+1}, z^{t}\right) B\left(z^{t+1}\right)=W_{t} L_{t}+\pi_{t}+M_{t-1}+B_{t}+T_{t}
$$

Here, $B\left(z^{t+1}\right)$ are contingent home-currency denominated nominal bonds whose prices at time $t$ are $q\left(z^{t+1}, z^{t}\right)$, where $z^{t}$ represents the state at time t. $\pi_{t}$ is the representative agent's share of profits from home firms. $T_{t}$ are monetary transfers from the government. $W_{t}$ is the wage rate.

The money demand equation for the representative home-country resident: 


$$
\frac{M_{t}}{P_{t}}=\frac{\chi^{1 / \varepsilon} C_{t}^{\rho / \varepsilon}}{\left(1-d_{t}\right)^{1 / \varepsilon}},
$$

where $d_{t}$ is the inverse of the gross nominal interest rate, given by

$$
d_{t}=E_{t}\left(\beta \frac{C_{t+1}^{-\rho} P_{t}}{C_{t}^{-\rho} P_{t+1}}\right) .
$$
real wage:

Consumers equate the marginal rate of substitution between leisure and consumption to the

$$
\frac{W_{t}}{P_{t}}=\frac{\eta V^{\prime}\left(L_{t}\right)}{C_{t}^{-\rho}},
$$

where $W_{t}$ is the wage rate.

Optimal risk sharing implies

$$
\frac{S_{t} P_{t}^{*}}{P_{t}}=\left(\frac{C_{t}}{C_{t}^{*}}\right)^{\rho}
$$

in equilibrium. Consumption will differ across the two countries only to the extent that there are changes in the real exchange rate. In the PCP model, since purchasing power parity holds, we have, as Obstfeld and Rogoff (1998) derive, $C_{t}=C_{t}^{*}$.

Government increases the money supply with direct transfers. The government budget constraint (in per capita terms) is simply

$$
M_{t}=M_{t-1}+T_{t}
$$

The firms are monopolistic competitors. The production function for firm $i$ is given by:

$$
Y(i)=L(i)
$$

Devereux and Engel (1998) derive the price-setting behavior of firms. Here we note only that the objective of the domestic firms is to set prices to maximize the expected utility of the owners, who are the domestic residents. Firms must set prices before information about the random domestic and foreign money supplies is known. No state-contingent pricing is allowed in any of the three models. Wages are perfectly flexible ex post, and firms hire as many workers as needed to produce output demanded at ex post prices. Wages adjust to insure supply of labor equals demand.

In the PCP model, $P_{h t}$ and $P_{f t}^{*}$ (the foreign-currency price of foreign goods) are predetermined at time t. Since the law of one price holds, so $P_{f t}=S_{t} P_{f t}^{*}$ and $P_{h t}^{*}=P_{h t} / S_{t}$, the 
prices $P_{f t}$ and $P_{h t}^{*}$ vary concurrently with the exchange rate. In the PTM model, all four nominal prices are predetermined.

We will specialize the term in the utility function to have real balances enter logarithmically $(\varepsilon \rightarrow 1)$. We will also assume that the money supply follows a random walk of sorts. Specifically:

$$
E_{t}\left(\frac{M_{t}}{M_{t+1}}\right)=1 .
$$

These two assumptions together imply nominal interest rates are constant. We can derive from equations (8) and (9):

$$
C_{t}^{\rho}=\left(\frac{1-\beta}{\chi}\right) \frac{M_{t}}{P_{t}}
$$

Intuitively, a monetary expansion leads to a decline in real interest rates (current consumption rises while next period's consumption is expected to be unaffected by a monetary shock) but an increase in expected inflation. When money follows a random walk and real balances enter utility logarithmically, movements in real interest rates and expected inflation rates always exactly offset each other. Nominal interest rates are constant.

Equations (10) and (11) together give us a very simple expression for the exchange rate:

$$
S_{t}=\frac{M_{t}}{M_{t}^{*}} .
$$

Now assume that money supplies are distributed logarithmically. So,

$$
m_{t+1}-m_{t}=\frac{1}{2} \sigma_{m}^{2}+v_{t+1}
$$

Here, $\sigma_{m}^{2}$ is the variance of the money supply, which is assumed to be constant over time.

It is useful to collect equations (10), (11) and (12) in log form:

$$
\begin{gathered}
s_{t}=p_{t}-p_{t}^{*}+\rho c_{t}-\rho c_{t}^{*} \\
\rho c_{t}=m_{t}-p_{t}+\ln (1-\beta / \chi) \\
s_{t}=m_{t}-m_{t}^{*}
\end{gathered}
$$

As an alternative to the money demand relationship derived from assuming real balances are in the utility function, let us consider a cash-in-advance constraint. We will assume that home residents must buy all goods with home currency, and foreign residents must buy all goods with foreign currency. This gives us: 


$$
\begin{aligned}
& m_{t}-p_{t}=c_{t} \\
& m_{t}^{*}-p_{t}^{*}=c_{t}^{*}
\end{aligned}
$$

The risk-sharing condition (14) still holds in this model. Together with equations (17) and (18) we arrive at this expression for the exchange rate:

$$
s_{t}=(1-\rho)\left(p_{t}-p_{t}^{*}\right)+\rho\left(m_{t}-m_{t}^{*}\right) \text {. }
$$

\section{Expressions for the Risk Premium}

In this section, we derive expressions for the risk premium in our various models. Discussion of the expressions is postponed until section 4. We shall consider the model with real balances in the utility function first, and then proceed to the cash-in-advance model. In all cases, we shall use equation (6) for the risk premium.

\section{Real Balances in the Utility Function}

In the PTM model, all goods prices are predetermined. So, using equations (6), (15), and (16), the risk premium in the PTM model given by:

$$
\begin{aligned}
r p_{t}^{P T M} & =-\rho \operatorname{Cov}_{t}\left(s_{t}, c_{t}\right) \\
& =-\rho \operatorname{Cov}_{t}\left(m_{t}-m_{t}^{*}, \frac{1}{\rho} m_{t}-\frac{1}{\rho} p_{t}\right) \\
& =-\rho \operatorname{Cov}_{t}\left(m_{t}, \frac{1}{\rho} m_{t}\right) \\
& =-\sigma_{m}^{2}
\end{aligned}
$$

In the PCP model, the domestic price of foreign goods fluctuates with the exchange rate. So, we have:

$$
p_{t}=n p_{h t}+(1-n) s_{t}+(1-n) p_{f t}^{*}
$$

We can then derive the risk premium in the PCP model from equations (6), (15), (16) and (21): 


$$
\begin{aligned}
r p_{t}^{P C P} & =-\rho \operatorname{Cov}_{t}\left(s_{t}, c_{t}\right) \\
& =-\rho \operatorname{Cov}_{t}\left(m_{t}-m_{t}^{*}, \frac{1}{\rho} m_{t}-\frac{1}{\rho}\left(n p_{h t}+(1-n) s_{t}+(1-n) p_{f t}^{*}\right)\right) \\
& =-\rho \operatorname{Cov}_{t}\left(m_{t}-m_{t}^{*}, \frac{1}{\rho}\left(n m_{t}+(1-n) m_{t}^{*}\right)\right. \\
& =-n \sigma_{m}^{2}+(1-n) \sigma_{m^{*}}^{2}
\end{aligned}
$$

It is easy to find the risk premium in the more general utility specification for real balances in which $\varepsilon \neq 1$ by examining the solutions for consumption and exchange rates in Devereux and Engel (1998). The risk premiums in the more general specifications are simply a multiple of the expressions given in equations (20) and (22). The factor multiplying these expressions is $\frac{1+i \varepsilon}{1+i}$, where $i$ is the steady-state nominal interest rate.

\section{Cash-in-Advance}

In the cash-in-advance model, equations (6), (17) and (19) give us the expression for the risk premium in the PTM model, recalling that goods prices are predetermined in that model:

$$
\begin{aligned}
r p_{t}^{P T M} & =-\rho \operatorname{Cov}_{t}\left(s_{t}, c_{t}\right) \\
& =-\rho \operatorname{Cov}_{t}\left(\rho\left(c_{t}-c_{t}^{*}\right)+p_{t}-p_{t}^{*}, c_{t}\right) . \\
& =-\rho^{2} \operatorname{Var}_{t}\left(c_{t}\right) \\
& =-\rho^{2} \sigma_{m}^{2}
\end{aligned}
$$

In the PCP model, we need to derive the solution for the exchange rate:

$$
\begin{aligned}
s_{t} & =(1-\rho)\left(p_{t}-p_{t}^{*}\right)+\rho\left(m_{t}-m_{t}^{*}\right) \\
& =(1-\rho) s_{t}+\rho\left(m_{t}-m_{t}^{*}\right), \\
& =m_{t}-m_{t}^{*}
\end{aligned},
$$

where we have used in the derivation that purchasing power parity holds in the PCP model.

Then we can derive from equation (6), (17) and (24): 


$$
\begin{aligned}
r p_{t}^{P C P} & =-\rho \operatorname{Cov}_{t}\left(s_{t}, c_{t}\right) \\
& =-\rho \operatorname{Cov}_{t}\left(m_{t}-m_{t}^{*}, m_{t}-n p_{h t}-(1-n) s_{t}-(1-n) p_{f t}^{*}\right) \\
& =-\rho \operatorname{Cov}_{t}\left(m_{t}-m_{t}^{*}, n m_{t}+(1-n) m_{t}^{*}\right. \\
& =-\rho n \sigma_{m}^{2}+\rho(1-n) \sigma_{m^{*}}^{2}
\end{aligned}
$$

\section{Interpretation}

To understand the nature of the risk premium in the sticky-price models, it is helpful to compare expressions (20), (22), (23) and (25) to the expression for the risk premium in Lucas's (1984) two-country asset-pricing model. In Lucas's model, prices are perfectly flexible. There effectively are complete asset markets. Output is determined exogenously, and varies over time due to random supply shocks. Money demand arises from cash-in-advance constraints.

While Lucas assumes that domestic agents need domestic money to buy home goods and foreign money to buy foreign goods, we will assume the cash-in-advance constraints given in equations (17) and (18). This will make no difference ultimately, because the expression we derive for the risk premium is exactly that derived by Engel (1992), which assumes the Lucas cash-inadvance constraint.

Since purchasing power parity holds in this model, and since the complete asset markets equalize home and foreign consumption, equations (17) and (18) give us

$$
s_{t}=m_{t}-m_{t}^{*}
$$

Output at home and abroad, $y_{t}$ and $y_{t}^{*}$ are exogenously given. In equilibrium, each agent consumes exactly the same amount of each good, and all of output is consumed. So:

$$
\begin{aligned}
r p_{t}^{\text {FLEX }} & =-\rho \operatorname{Cov}_{t}\left(s_{t}, c_{t}\right) \\
& =-\rho \operatorname{Cov}_{t}\left(m_{t}-m_{t}^{*}, n y_{t}+(1-n) y_{t}^{*}\right) \\
& =-\rho n \operatorname{Cov}_{t}\left(m_{t}, y_{t}\right)+\rho n \operatorname{Cov}_{t}\left(m_{t}^{*}, y_{t}\right)-\rho(1-n) \operatorname{Cov}_{t}\left(m_{t}, y_{t}^{*}\right)+\rho(1-n) \operatorname{Cov}_{t}\left(m_{t}^{*}, y_{t}^{*}\right)
\end{aligned} .
$$

\section{Endogeneity of Risk Premium in Sticky-Price Models}

It is clear from equation (26) that the risk premium in the Lucas model arises out of correlations between exogenous money supplies and exogenous supply shocks. If those correlations were zero, the risk premium would be zero. Engel (1992) emphasizes this fact, and points out that much of the literature is misleading on the source of the risk premium in the Lucas model. Because that literature incorrectly focuses on $f_{t}-E_{t}\left(s_{t+1}\right)$ as the measure of the risk premium, it misses the importance of the covariance between monetary and real shocks. Engel (1992) cites several papers which assume the covariance of monetary and real shocks are zero in the Lucas model. The risk premium ought to be zero, but those papers add in the Jensen's inequality terms as part of the risk 
premium. The Jensen's inequality terms are non-zero even when real and monetary shocks are uncorrelated. Hence, the literature mistakenly derives expressions for the risk premium that are functions of the variances of monetary and real shocks, because the Jensen's inequality terms are functions of the variances. As equation (26) shows, only the covariances of monetary and real shocks matter for the risk premium in the Lucas model.

But, all of the expressions for the risk premium in the sticky-price models ((20), (22), (23) and (25)) involve only the variance of home and foreign money supplies. The reason is that shocks to money generate changes in exchange rates and consumption. So, exchange rates and consumption can covary even when there are only monetary shocks. While ultimately the foreign exchange risk premium depends on there being a correlation between monetary and real variables, in sticky-price models that correlation arises endogenously.

One appealing feature of the risk premiums generated in the sticky-price models is that the size of the risk premium is directly related to the volatility of the nominal exchange rate. In the Lucas model, by contrast, when exchange rate volatility is reduced, the risk premium is only reduced if there is a parallel reduction in the covariance of real and monetary shocks. Flood and Rose (1996) find that deviations from uncovered interest parity are lower in the EMU, where exchange rates are less volatile.

\section{Productivity Shocks Do Not Matter for the Risk Premium in Sticky-Price Models}

Not only can we generate a foreign exchange risk premium in sticky-price models with monetary variance alone, but also productivity shocks do not affect the risk premium in the models we have examined. We did not introduce productivity shocks into the sticky-price model, but we can do that by adding a multiplicative aggregate productivity shock for each industry, so that output is given by:

$$
Y_{t}(i)=\theta_{t} L_{t}(i)
$$

But the output equation plays no role in determining either consumption or the exchange rate in the models we have examined. Equations (14), (15) and (16) completely determine the covariance of the exchange rate with consumption in the real-balances-in-the-utility-function model. Equations (14), (17), (18) and (19) determine that covariance in the cash-in-advance model.

If we allowed real balances to enter utility in a form more general than logarithmic (so $\varepsilon \neq 1$ ), there is a channel through which productivity shocks could affect the risk premium. The productivity shocks could affect the nominal interest rate, which in turn could influence consumption.

Interestingly, that channel is not open in the cash-in-advance formulation of the sticky-price model. So, while the stochastic properties of productivity shocks are key to determining the risk premium in the cash-in-advance Lucas model, they play no role in the cash-in-advance sticky-price models. 


\section{There is No Unique Risk Premium in PTM Models}

As Engel (1984) emphasizes, the measure of the risk premium requires a measure of the price index of consumption goods. When individuals consume different baskets, or when they face different prices, the price indexes will be different. Then, the risk premium will not be the same for all individuals.

In the PTM models we have presented, the law of one price does not hold. So, individuals in each country face different price indexes. It is easy to see in our general equilibrium models how failure of purchasing power parity affects the risk premium. In the class of models we examine, the risk premium is given by $-\rho \operatorname{Cov}_{t}\left(s_{t}, c_{t}\right)$ for home residents and $-\rho \operatorname{Cov}_{t}\left(s_{t}, c_{t}^{*}\right)$ for foreign residents. From equation (10) we find that if purchasing power parity holds, then $c_{t}=c_{t}^{*}$ and the two measures of the risk premium are the same.

In the PTM model, where consumption is not equal across countries, the risk premium for foreign residents is not the same as the expressions given in equations (20) and (23). Those equations show that for the home resident, the risk premium is a function only of home country monetary variance. The analogous expressions for the foreign resident are functions of foreign monetary variance. In the real-balances-in-the-utility-function model, the risk premium is $-\sigma_{m^{*}}^{2}$ for foreigners. In the cash-in-advance framework, the risk premium for foreign residents is $-\rho^{2} \sigma_{m^{*}}^{2}$.

Engel suggests testing the null hypothesis of no risk premium and efficient markets by testing the hypothesis that $\frac{F_{t}-S_{t+1}}{P_{t+1}}$ has a conditional mean of zero. But that test depends on the choice of price index. As stated, the null is that there is no risk premium for domestic residents. The analog for no foreign risk premium is to put the foreign price level in the denominator (converted into domestic currency units). That is, $\frac{F_{t}-S_{t+1}}{S_{t+1} P_{t+1}^{*}}$ should have a conditional mean of zero. This is equivalent to $\frac{F_{t}^{*}-S_{t+1}^{*}}{P_{t+1}^{*}}$ having a conditional mean of zero, where $F_{t}^{*} \equiv 1 / F_{t}$ and $S_{t}^{*} \equiv 1 / S_{t}$

\section{The Size of the Risk Premium}

In the PCP and PTM models in which money demand arises from the assumption that real balances are in the utility function, the risk premium is independent of the degree of risk aversion. (See equations (20) and (22). Obstfeld and Rogoff (1998) make this point for the PCP model.) That might initially seem puzzling since $r p_{t} \equiv-\rho \operatorname{Cov}_{t}\left(s_{t+1}, c_{t+1}\right)$. But the covariance term declines as $\rho$ rises. This occurs because the variance of consumption is inversely related to $\rho .{ }^{1}$ So, large

\footnotetext{
${ }^{1}$ The correlation between $s$ and $c$ is independent of $\rho$.
} 
values of $\rho$ are associated both with more risk aversion and less risk. As $\rho$ goes to zero, the variance of consumption goes to infinity, so even when individuals are nearly risk neutral the size of the risk premium does not decline.

These models are incapable of generating large risk premiums. We can make an argument similar to those in Engel $(1992,1996)$, which pertained to the Lucas model. For example, suppose that a $95 \%$ confidence interval for the money growth rate was \pm 7 percent per year. This is surely a generously wide confidence interval. It implies a standard deviation of money growth of about 4 percent at annualized rates, or 0.04. The variance of money growth, then, is 0.0016. So, the PTM model with money in the utility function can only generate a risk premium of much less than one percentage point, since it has a value of the risk premium of $-\sigma_{m}^{2}$. In the PCP model, the risk premium would be even smaller in the symmetric case of equal domestic and foreign monetary variances. There the risk premium is (from equation (22)) $(1-2 n) \sigma_{m}^{2}$.

(The risk premium in the more general specification in which $\varepsilon \neq 1$ could be larger, since the value of the risk premium more generally is $\frac{1+i \varepsilon}{1+i}$ times the values taken from equations (20) and (22). But, unless $\varepsilon$ is extremely large, implying both low income and interest elasticities of money demand, the risk premium would still be small.)

In the PCP model with the cash-in-advance constraint the risk premium could be larger, depending on the value of $\rho$. In the symmetric case, the risk premium is $\rho(1-2 n) \sigma_{m}^{2}$. Still, with a plausible value for $\rho$ of 5 , and with $n=1$, the risk premium is less than one percentage point. Note, however, that the Lucas model could only generate risk premiums this high if the covariance of real productivity shocks and money growth shocks were as high as the variance of money supply shocks.

The interesting case is the PTM model with the cash-in-advance constraint. In this case, the risk premium is $-\rho^{2} \sigma_{m}^{2}$. Here with a value of $\rho$ equal to 5, and a variance of money growth equal to 0.0016 , we get a risk premium of 0.04 , or 4 percentage points. This is very close to the size of the conditional risk premiums that many studies on U.S. data have found (see Engel (1996) for a survey of the empirical literature.)

To generate risk premiums even close to this size in neoclassical models, researchers have had to resort to models where some of the axioms of expected utility are not satisfied. These models of "first-order" risk aversion generate risk premiums that are not of the form of $\rho$ times a variance (or covariance), but rather $\rho$ times a standard deviation. (See, for example, Bekaert, Hodrick and Marshall (1997).)

Intuitively, why does the risk premium in this model depend on the square of $\rho$ ? The log of the exchange rate is linearly related to the $\log$ of consumption with a factor of $\rho$ on the $\log$ of consumption. Hence, the covariance of the log of the exchange rate with the log of consumption rises with $\rho$. Since the amount of risk aversion increases linearly with $\rho$ as well, the risk premium is proportional to the square of $\rho$. 
A case can be made that this is a plausible formulation. First, empirical evidence suggests that almost all of the short-term volatility in real exchange rates comes from volatility in nominal exchange rates (see, for example, Engel (1999).) This is consistent with the PTM model. If the risk-sharing condition (14) is true, the covariance of the exchange rate with consumption must be $\rho$ times the variance of consumption. Even if one were not willing to accept the assumption that asset markets are complete, it is plausible that equation (14) is the right order of magnitude. When purchasing power parity fails, even complete asset markets do not eliminate country-specific risk. But, the more risk averse individuals are, the more risk sharing is likely to occur. So, equation (14)'s implication that the standard deviation of relative consumption is equal to $1 / \rho$ times the standard deviation of the exchange rate with consumption is natural.

No matter how money demand is modeled, the PTM set-up along with the risk-sharing equation (10) gives us that $\operatorname{Cov}_{t}\left(s_{t}, c_{t}\right)=\rho \operatorname{Var}_{t}\left(c_{t}\right)-\rho \operatorname{Cov}_{t}\left(c_{t}, c_{t}^{*}\right)$. In the models we have examined, $\operatorname{Cov}_{t}\left(c_{t}, c_{t}^{*}\right)=0$ so $\operatorname{Cov}_{t}\left(s_{t}, c_{t}\right)=\rho \operatorname{Var}_{t}\left(c_{t}\right)$. Since we have the risk premium given by $r p_{t} \equiv-\rho \operatorname{Cov}_{t}\left(s_{t+1}, c_{t+1}\right)$, the risk premium must be $r p_{t} \equiv-\rho^{2} \operatorname{Var}_{t}\left(c_{t+1}\right)$. Thus, sticky-price models of the PTM variety, with a risk-sharing condition that implies there is more consumption smoothing as the degree of risk aversion increases, naturally give rise to a risk premium equal to the square of the risk aversion coefficient times the variance of consumption.

This result is not dependent on the cash-in-advance formulation. Indeed, this result holds even in our real-balances-in-the-utility-function model. But that model has the unfortunate property that the variance of consumption is $1 / \rho^{2}$ times the variance of the money supply, so the coefficient of risk aversion drops completely out of the expression for the risk premium. But if the link between consumption variance and the variance of money growth does not depend on $\rho$, then the PTM model will produce much larger risk premiums than models that assume purchasing power parity (either with sticky prices or without.)

\section{Conclusions}

While the PTM model is capable of producing large enough risk premiums to match the data, there is another empirically puzzling aspect to the foreign exchange risk premium that has not yet been addressed here. As Engel (1996) emphasizes, models of the risk premium also need to generate correlations between the risk premium and the forward premium in order to explain the uncovered interest parity puzzle. In the data $\frac{F_{t}-S_{t+1}}{P_{t+1}}$ is positively correlated with $F_{t}-S_{t}$. In $\log$ terms, the risk premium as we have defined it, $r p_{t}$ must be positively correlated with the interest differential, $i_{t}-i_{t}^{*}$ to be able to explain that empirical regularity.

The models presented in this paper have assumed a constant variance of the money supply, which implies constant risk premiums. To generate this correlation, time-varying variances need to be introduced. 
Consider the PTM model with the cash-in-advance constraint. Since the risk premium is given by $-\rho^{2} \sigma_{m}^{2}$, we need a negative correlation between monetary variance and $i_{t}-i_{t}^{*}$ to get the desired correlation between the risk premium and the interest differential. Such a model is beyond the scope of this paper. But, if an increase in the money supply lowers nominal interest rates (as it would in the constant-variance version of this model), then we need that the variance of money growth rates increases with the level of the money supply.

Bekaert, Hodrick and Marshall (1997) show that the nominal interest rate volatility predicted in flexible-price general equilibrium models is far too great relative to the size and variance of the risk premium. It seems that the sticky-price models have some potential of resolving this issue. We have seen that when the money supply follows a random walk and real balances enter the utility function logarithmically, nominal interest rates are constant. That property holds whether the second moments of money are constant or not. In that case we can build a model with a timevarying risk premium with completely stable nominal interest rates. However, it was the cash-inadvance formulation, not the money-in-the-utility model, that held the greatest promise for generating large risk premiums. In the cash-in-advance model with random-walk money, nominal interest rates are no longer constant.

It is an open question whether one could build a PTM model with an empirically plausible money demand and money supply specification that could explain the uncovered interest parity puzzle. But, this appears to be a promising avenue for future research. 


\section{References}

Bekaert, Geert; Robert J. Hodrick; and David A. Marshall, 1997, The implications of first-order risk aversion for asset market risk premiums, Journal of Monetary Economics 40, 3-39.

Devereux, Michael B., and Charles Engel, 1998, Fixed vs. floating exchange rates: How price setting affects the optimal choice of exchange-rate regime, National Bureau of Economic Research, working paper no. 6867.

Engel, Charles, 1984, Testing for the absence of expected real profits from forward market speculation, Journal of International Economics 17, 299-308.

Engel, Charles, 1992, On the foreign exchange risk premium in a general equilibrium model, Journal of International Economics 32, 305-319.

Engel, Charles, 1996, The forward discount anomaly and the risk premium: A survey of recent evidence, Journal of Empirical Finance 3, 123-192.

Engel, Charles, 1999, Accounting for U.S. real exchange rate changes, Journal of Political Economy, forthcoming.

Flood, Robert P., and Andrew K. Rose, 1996, Fixes: Of the forward discount puzzle, Review of Economics and Statistics 78, 748-752.

Hodrick, Robert, 1987, The empirical evidence on the efficiency of forward and futures foreign exchange markets (Chur: Harwood).

Obstfeld, Maurice, and Kenneth Rogoff, 1995, Exchange rate dynamics redux, Journal of Political Economy 103, 624-660.

Obstfeld, Maurice and Kenneth Rogoff, 1998, Risk and exchange rates, National Bureau of Economic Research, working paper no. 6694.

Stulz, Rene, 1984, Currency preferences, purchasing power risks, and the determination of exchange rates in an optimizing model, Journal of Money, Credit and Banking 16, 302-316. 